\title{
Gênero, gerações e espaço doméstico: trabalho, casa e família
}

\author{
Mara Coelho de Souza Lago ${ }^{1}$ \\ Carolina Duarte de Souza \\ Erikson Kaszubowski \\ Marina Silveira Soares \\ Universidade Federal de Santa Catarina, Florianópolis-SC, Brasil
}

\begin{abstract}
Resumo: Com as mudanças conceituais trazidas pelo "feminismo das diferenças", os estudos feministas reavaliaram os pólos de valorização positiva e negativa das posições de mulheres e homens, voltando sua atenção para características, atribuições e funções femininas. Como consequência destas reflexões e das práticas que elas orientam, abriu-se a possibilidade de um olhar valorativo sobre o espaço doméstico e o trabalho que homens e mulheres nele desempenham. Esta pesquisa objetivou realizar um estudo de gênero sobre a casa, analisando as relações dos sujeitos com seus espaços de vida familiar, no interesse da valorização do trabalho doméstico e da compreensão do seu valor subjetivo. A pesquisa teve enfoque qualitativo a partir da abordagem etnográfica, por meio de entrevistas livres, gravadas e filmadas, objetivando obter depoimentos e imagens de sujeitos em suas casas e atividades. Foram entrevistados 12 mulheres e 5 homens de diferentes gerações e atividades profissionais, no município de Antônio Carlos, Região Metropolitana de Florianópolis-SC.
\end{abstract}

Palavras-chave: gênero, trabalho doméstico, urbanização.

\section{Gender, generations and domestic environment: work, house and family}

\begin{abstract}
With the conceptual changes brought by the "difference feminism", feminist studies re-evaluated the poles of positive and negative valorization of women's and men's roles, focusing on feminine characteristics, attributions and functions. As a consequence of these studies and practices they guide, it was possible to value the domestic environment and tasks that both men and women perform in this environment. This study aimed to develop a gender study about the house, analyzing the relationship of the individuals with their family life spaces, trying to value the domestic work and to understand its subjective meaning. This qualitative study with ethnographic approach was carried out through taped and video recorded free interviews aiming to capture the testimonials and images of the participants in their homes during tasks. A total of 12 women and 5 men from different generations and professions were interviewed in Antônio Carlos in the metropolitan region of Florianópolis, SC, Brazil.
\end{abstract}

Keywords: gender, household management, urbanization.

\section{Género, generaciones, espacio doméstico: trabajo, casa y familia}

Resumen: Con los cambios conceptuales originados por el "feminismo de las diferencias", los estudios feministas reevaluaran los polos de valorización positivos y negativos de las posiciones de mujeres y hombres, centrándose en características, atribuciones y funciones femeninas. Como consecuencia de estas reflexiones y de las practicas por ellas orientadas, fue posible observar de forma valorativa el espacio doméstico y al trabajo que hombres y mujeres allí realizan. Esta investigación tenía como objetivo realizar un estudio de género acerca de la casa, analizando la relación de los sujetos con sus espacios de vida familiar, tratando de valorizar el trabajo doméstico y de entender su significado subjetivo. Se trata de una investigación cualitativa, de enfoque etnográfico, que a través de entrevistas libres, grabadas y filmadas, captaron testimonios e imágenes de los sujetos, en sus casas, haciendo sus actividades. Fueron entrevistados 5 hombres y 12 mujeres de distintas generaciones y profesiones, en el municipio de Antonio Carlos, Región Metropolitana de Florianópolis-SC, Brasil.

Palabras clave: género, trabajo doméstico, urbanización.

Os estudos de gênero, que vêm substituir os estudos da mulher, estiveram sempre atrelados às reivindicações dos movimentos feministas. A partir de uma divisão, sempre arbitrária, convencionou-se separar dois momentos desse movimento. Os feminismos da primeira onda, final do século XIX, início do XX, em que as reivindicações eram pelo direito ao voto, ao trabalho remunerado, à cidadania, à igualdade (Pedro, 2005).

\footnotetext{
1 Endereço para correspondência:

Profa. Dra. Mara Coelho de Souza Lago. Universidade Federal de Santa Catarina. Centro de Filosofia e Ciências Humanas. Departamento de Psicologia. Campus Universitário-Trindade. CEP 88.040-970. Florianópolis-SC, Brasil.E-mail: mlago@cfh.ufsc.br
}

Os movimentos feministas pela igualdade de direitos lutavam pelo reconhecimento das capacidades das mulheres, seu acesso à educação e às profissões e funções que lhes eram dificultadas pela naturalização das características diferenciais que lhes eram atribuídas. A conquista desse reconhecimento acompanhou a sobrevalorização das funções masculinas que as mulheres lutavam por atingir, em detrimento das funções e afazeres que lhes eram atribuídos tradicionalmente. Em nossas pesquisas com camadas médias (Lago, Figueiredo, \& Serafim, 2000), ao perguntarmos a uma mulher se ela trabalhava, era comum a resposta: "Não, não trabalho. Só em casa”. Enquanto o trabalho doméstico era desqualificado como não trabalho, não remunerado, as funções no "mundo público" eram supervalorizadas, como o trabalho "fora", em troca de remuneração ou salário. 
Uma das dicotomias que organizaram o pensamento moderno consistiu na separação entre as esferas pública e privada, que se constituiu como efeito da ascensão da burguesia, no modo capitalista de produção. Nesta dicotomização, as mulheres foram destinadas às funções nos espaços privados, enquanto os homens tiveram acesso aos espaços públi$\cos$ de trabalho. As funções valorizadas eram as exercidas nos espaços públicos, de decisões políticas, enquanto os trabalhos realizados nos espaços domésticos, privados, foram sempre considerados de menor valor.

O chamado feminismo de segunda onda, que teve início com o recrudescimento das reivindicações feministas dos anos 1960 nos Estados Unidos e Europa (anos 1970 no Brasil), também lutavam por igualdade de direitos, salários, autonomia (Pedro, 2005; Nogueira, 2001). Nesta segunda onda dos movimentos feministas se desenvolveram, ao lado dos feminismos da igualdade, os feminismos das diferenças (Greer, 1974; Firestone, 1976; Gilligan, 1982), que ressignificaram os pólos de valorização positiva e negativa das esferas pública e privada, passando a enaltecer as características, atribuições e funções femininas. Estas novas versões dos estudos e movimentos feministas levaram a um olhar recuperador da importância para as funções delegadas às mulheres em nossas culturas.

Mulheres e homens começaram a contar outras histórias, a recuperar falas que estiveram silenciadas, a se voltar para a análise das práticas cotidianas (Perrot, 1998), a considerar as dimensões subjetivas nelas implicadas. Assim, as palavras de ordem feministas, "o privado é político", passaram a embotar as fronteiras entre público e privado.

Uma das principais consequências destas reflexões e das práticas que as orientam é a possibilidade de um olhar valorativo para a casa, o doméstico, o trabalho que inúmeras mulheres continuam a desempenhar. Muitas vezes como única forma de trabalharem "fora", em troca de salário, carteira assinada, ou como diaristas, sem quaisquer direitos trabalhistas, mas como mulheres que conseguem ainda trabalhos remunerados em muitas das nossas periferias urbanas.

As análises do espaço doméstico ganham importância no estudo de sujeitos urbanos na atualidade, em que se imbricam com a questão do individualismo como ideologia dominante (Dumont, 1985) e como modo de vida. É neste espaço que os sujeitos se isolam cada vez mais. As casas se fragmentam continuadamente nos espaços privados, individuais, onde os sujeitos passam a permanecer por muito mais tempo, sem interação com os outros moradores, diminuindo a utilização daqueles espaços partilhados das residências. Foi possível, assim, que nos debruçássemos sobre este objeto, a casa - seu desvalor ou sua valorização para as mulheres que dela cuidam - e para os sujeitos que nela habitam.

No centro das análises desta pesquisa há a concepção de que o processo de constituição do sujeito se dá no sentido da individuação de um ser cultural. A criança nasce em estado de absoluto desamparo (Freud, 1930/1990), necessitando de cuidados, compreendidos como função de mãe e função de pai (Lacan, 1938/2002), para se constituir como sujeito na linguagem. O sujeito é falado antes de falar; e, se pode dizer $e u$ de si mesmo, é porque nos processos inconscientes de identificações vai construindo a memória de si. Sujeito do desejo, sujeito do significante em diferentes posições simbólicas - de gênero, gerações, classe, etnia e outras diferenças que se façam presentes em variados contextos e situações históricas (Lacan, 1966/1998).

A categoria gênero começou a ser utilizada nos estudos sobre as mulheres, para marcar a condição relacional da construção cultural de masculinidades e feminilidades. Se num primeiro momento o conceito foi usado para contrapor ao sexo (biológico) o gênero (cultural) (Stoller, 1968), esta oposição foi sendo gradativamente problematizada. No texto muito citado de Joan Scott (1995, p. 86), "o gênero é um elemento constitutivo de relações sociais fundadas sobre as diferenças percebidas entre os sexos (...) e uma forma primária de dar significado às relações de poder". Laqueur (2001) desconstrói a dicotomia sexo/gênero, afirmando a proeminência do gênero sobre o sexo, quando historiciza a concepção do modelo de sexo único, como anterior àquele que estabelece e enfatiza a diferenciação sexual.

Quando vamos a campo pesquisar nossos informantes, as diferentes posições dos sujeitos se impõem aos nossos olhares - mulheres e homens, de variadas origens étnicas, constituídos em diferentes classes sociais, habitantes do campo ou da cidade, com modos de vida e formas de trabalho diferenciados, sujeitos de gerações, que "vivem uma certa não contemporaneidade de contemporâneos", como refere Motta (2004), reportando-se a uma concepção de Mannheim (1982).

A geração, para Sirinelli (2002), é uma reconstrução do pesquisador que classifica e rotula o tempo. Mannheim (1982) a conceitua como um fenômeno de localização social, que ocorre somente pela existência, na interação entre seres humanos, de uma estrutura social definida e pelo fato da história basear-se em um tipo particular de continuidade. $\mathrm{O}$ recorte geracional aponta a uma restrição imposta aos sujeitos pertencentes a uma mesma geração, qual seja, a uma gama específica de experiência potencial que os predispõem a um modo característico de pensamento e experiência e a um tipo peculiar de ação historicamente relevante. Uma geração, enquanto realidade, existe apenas quando é criado um vínculo concreto entre os membros de uma mesma faixa etária, através de sua exposição aos sintomas sociais e intelectuais de um processo de desestabilização dinâmica. A coexistência e a comunicação entre as gerações precedentes e seguintes fazem com que, em cada momento e em todas as sociedades, estejam presentes pelo menos três tipos singulares de discursos sobre os acontecimentos, sendo um tipo específico para cada faixa geracional (Pomian, 1984).

Esta linha de pesquisa, centrada no estudo de sujeitos que vivenciam a urbanização de seus espaços de vida e trabalho, que iniciou com os descendentes de açorianos em Florianópolis (Lago, 1992, 1996), dirigiu-se para os descendentes 
de alemães que fundaram a colônia de São Pedro, próxima à Florianópolis-SC. Colonos que viviam da agricultura, em lavoura de pequena propriedade, produzindo para o consumo com mão de obra familiar e que, buscando novas terras para cultivo nos arredores, fundaram outras colônias, como a que deu origem ao município de Antônio Carlos-SC, local onde foi realizada a pesquisa.

As falas dos sujeitos articularam questões referentes à comunidade, família, gênero, gerações, etnia, trabalho, escolaridade, assim como à urbanização, já que o município de Antônio Carlos vem experimentando significativas transformações de seus modos de vida, em função do processo de incorporação à Região Metropolitana de Florianópolis.

\section{Método}

\section{Participantes}

Para a realização da pesquisa foram entrevistadas 17 pessoas, sendo 12 mulheres e 5 homens. As idades das mulheres variaram entre 84 e 12 anos: cinco idosas, uma mulher na faixa dos 50 anos, quatro entre 30 e 45 anos e duas adolescentes, de 12 e 15 anos. As idades dos homens variaram entre 30 e 52 anos.

A proposta de pesquisa foi submetida ao Comitê de Ética em Pesquisa com Seres Humanos da Universidade Federal de Santa Catarina, tendo sido aprovada. As mulheres e homens entrevistados foram previamente esclarecidos sobre a natureza e objetivos da pesquisa, e assinaram o Termo de Consentimento Livre e Esclarecido referente ao projeto.

\section{Procedimento}

Foram feitas várias incursões ao campo, todas registradas nos diários de campo, a partir das observações e experiências particulares de cada pesquisador. Inicialmente, os pesquisadores estiveram acompanhados de uma informante que os apresentou aos primeiros sujeitos entrevistados, e também a pessoas que haviam participado de pesquisa anterior. Em seguida, foram encontrados novos sujeitos dispostos a darem seus relatos, tanto por indicação daqueles que já estavam participando da pesquisa, como por meio de contatos feitos espontaneamente em visitas ao município.

Foram realizadas entrevistas livres, sendo que seis sujeitos (um homem e cinco mulheres) tiveram suas entrevistas filmadas, sendo as demais gravadas apenas em áudio. Procurou-se obter depoimentos sobre a casa, o espaço e o trabalho doméstico. Ainda, foram fotografadas e filmadas as casas dos informantes, procurando dar relevo, neste material, tanto à arquitetura e ambiente circundante, quanto aos espaços internos das residências e os usos que deles faziam seus moradores.

\section{Análise de dados}

Para a realização dessa pesquisa foi utilizado o método etnográfico. A etnografia implica em dois momentos irredutíveis, definidos por Oliveira (2000) a partir das expressões usadas por Geertz (1996) de estar lá e estar aqui. No primeiro, através de olhar e ouvir, o pesquisador observa e apreende a comunidade estudada em suas incursões ao campo; no segundo, pela apropriação reflexiva das experiências vivenciadas na pesquisa empírica, deve organizá-las na escrita etnográfica. O pesquisador apreende, inicialmente, a complexa estrutura conceptual que constitui a cultura estudada, para procurar descrevê-la abordando o comportamento e a ação humana na intrincada rede de significações compartilhadas a que cada ato remete, rede que é construída pelo homem, e que o captura (Geertz, 1996).

Antes mesmo da experiência de observação participante no campo, o pesquisador já tem seu olhar disciplinado pelos esquemas conceituais de sua matriz disciplinar, nas teorias que o orientam seu modo de perceber o mundo. Nesse sentido, o olhar é constituinte do objeto, pois um elemento visual emerge do ambiente investigado quando dele provém uma cadeia de sentidos aprendidos a partir da teoria, o que permite uma compreensão da realidade de maneira diferenciada (Oliveira, 2000).

É na observação participante que o olhar e o ouvir do pesquisador são voltados para a tentativa de compreender as significações culturais a partir de sua interioridade, pois esta inserção na sociedade estudada lhe permite observar as interações entre os sujeitos, ao mesmo tempo em que seu estranhamento permite esquadrinhar as maneiras como elas ocorrem, possibilitando elaborar uma ficção interpretativa que torne compreensíveis determinados elementos do sistema cultural pesquisado (Geertz, 1996).

É a partir da audição que os rituais, comportamentos e interações observados podem adquirir certa inteligibilidade na fala dos informantes. As entrevistas permitem, mesmo com limitações, uma aproximação do pesquisador ao modelo nativo (Oliveira, 2000), ou, como tradutor de um sistema exótico para a sua própria linguagem (Da Matta, 1981). O estranhamento é uma atitude epistêmica característica da Antropologia Social, que permite ao pesquisador superar o etnocentrismo e dar abertura à complexidade constituinte da cultura estudada (Oliveira, 2000). Fonseca (1999) o define como a etapa do trabalho etnográfico que permite dar visibilidade a comportamentos, padrões de interação, ou rituais que poderão ser investigados com maior profundidade no decorrer da pesquisa. Certamente, uma vez que nos constituímos como sujeitos na cultura, torna-se impossível um distanciamento completo, como afirma Da Matta (1981, p. 29), "o exótico nunca pode passar a ser familiar, e o familiar nunca deixa de ser exótico".

Esse disciplinarização visa possibilitar ao pesquisador a tentativa de estabelecer "uma ponte entre dois universos de significação" (Da Matta, 1981, p. 27). Geertz (1996), ressalta que a etnografia é um método em que o pesquisador tenta, a todo momento, compreender o que está sendo dito, por mais que essa compreensão seja permeada por inúmeros hiatos, faltas e assimetrias. Como o universo simbólico do pesquisador é invariavelmente diverso daquele dos sujeitos 
pesquisados, essa compreensão só pode advir a partir de um movimento de interpretação, ou seja, uma tentativa de aproximação desses universos, na esperança de se alcançar um horizonte comum que possibilite algum grau de troca simbólica. Uma vez que o etnógrafo só tem acesso à cultura pesquisada pelas palavras e ações de seus interlocutores, a etnografia se constitui como uma interpretação de interpretações (Geertz, 2005).

O segundo momento do método etnográfico configura-se no estando aqui, no qual o pesquisador transforma as experiências do campo em texto pelo uso de suas funções cognitivas, produzindo conhecimento. Nessa transposição feita da cultura pesquisada às elaborações teóricas próprias da disciplina do pesquisador, este trabalha suas interpretações a partir de um diálogo com construções teóricas já estabelecidas, inscrevendo os eventos ocorridos em um relato sobre a cultura estudada (Geertz, 1996).

Pautando-nos na fundamentação teórica descrita acima, o material obtido com o trabalho de campo desta pesquisa foi transcrito e cuidadosamente discutido pelos pesquisadores. A partir de reiteradas leituras, as falas dos sujeitos foram organizadas em torno de núcleos temáticos comuns, e interpretadas em termos de sua significância em relação ao tema em questão e aos modos de vida dos sujeitos.

\section{Resultados e Discussão}

\section{O município como comunidade}

Segundo Bauman (2003), a palavra comunidade evoca uma sensação boa, de pertencimento, um ideal de segurança, sendo aquilo que falta às pessoas e que as completaria. Do lado de fora há o perigo e a necessidade de maior atenção em relação aos outros. Há, porém, um preço a ser pago, já que é necessário também abdicar de alguma liberdade, do "direito à auto-afirmação". Assim, embora esses sejam valores essenciais para nós, não há como ajustar de forma equilibrada liberdade e segurança, pois quanto mais se tem uma, menos se tem a outra (Bauman, 2003). Esta ambivalência em relação à localidade, vista como comunidade, está explicitada no relato de uma das entrevistadas:

O município, quanto menor, eu acho que eles, o pessoal todo se conhece, e cobra mais. Se eles não fizerem o pessoal tá cobrando. É, tem muita gente vindo de fora, que a gente nem conhecia. A família que tá ali era de Barreiros, e eles voltaram pra cuidar dos filhos. Ela até comentou comigo assim, da escola, e aqui não é um lugar tão violento como na cidade. Por isso eles vieram morar pra cá. Às vezes tem gente que não quer sair também dos lugares mais movimentados. Vem pra cá e: "Ai que tédio! Que silêncio! Não tem movimento!’. E longe não, porque daqui a Florianópolis num instantinho tá lá. (Mulher, 31 anos)
Esta entrevistada trabalha em supermercado, aos finais de semana toma conta da casa e do filho, cuidado pela babá que também se responsabiliza pelos afazeres domésticos durante a semana. Ela e o marido estão vivenciando as mudanças pelas quais o município passa, e falam sobre sua relação com aqueles que vêm de fora. Ele é pedreiro, responsável pela construção de diversas casas no município, bem como por restaurações de casas antigas de estilo germânico. A seguir seu depoimento sobre os que vêm de fora:

Tem pessoas boas, mas nem todas. E a gente não sabe né, porque a gente não conhece. Agora já é bom, mas de agora em diante a tendência é ser pior. Não vem mais porque o terreno aqui é caro, então até por isso é bom. Porque não é qualquer um que consegue comprar e construir. Se fosse baratinho, qualquer coisa vinha pra cá. Assim, se é mais caro, o pessoal, assim, que vem pra cá, é mais da alta né. São pessoas melhores do que se fosse da favela também, né. Senão tava bem mais lotado isso aí. (Homem, 32 anos)

Nessas falas podemos perceber o desconhecimento a respeito daqueles que vêm para o município, o quanto isso é visto como tendência de que as coisas piorem, pois o desconhecido traz insegurança. Para proteger a comunidade são necessárias uma luta constante e uma vigilância permanente contra esses que vêm de fora (Bauman, 2003). É preciso manter os preços dos terrenos, para que não seja qualquer um a entrar na comunidade e para que a invasão se dê de forma menos rápida e acessível.

A comunidade, então, não é exatamente aquilo que sonhamos e buscamos, pois nela, ao mesmo tempo em que encontramos a segurança perdida nas grandes cidades, encontramos o "tédio" (Bauman, 2003), como falou uma das entrevistadas. Vários dos sujeitos que voltam ao município, em busca da segurança em morar ali, acabam por sentir falta do que tinham na "cidade grande", estranhando o extremo silêncio, o barulho das aves (e não dos carros). Como esse casal que saiu do município para trabalhar, mas acabou voltando para junto de seus próximos, deixando em BlumenauSC amigos, casa e negócios: “Acostumei, né. Era bom. É, já dá saudade de lá, né, que a gente deixou tudo. Mas assim tá bom" (Mulher, 45 anos); "Falta a gente sente, porque a gente tem os amigos lá. E vai pra lá e conversa um pouco. Dois, três dias lá, e volta" (Homem, 52 anos).

Existem diversas ambivalências nas falas, que expressam os prós e os contras em morar na comunidade, como a distância. Antônio Carlos é relativamente distante e, ao mesmo tempo, próxima da capital. Longe, ao menos por enquanto, da violência e da pobreza, e perto, pois se chega em poucos minutos ao local de trabalho de automóvel, pelo menos para quem vai trabalhar todos os dias fora da cidade, em Florianópolis ou arredores. Assim, aqueles que voltaram para o município fizeram-no em busca de melhor qualidade 
de vida: "Aqui a gente vive melhor, é. Lá... muito barulho. Aqui é um lugar mais calmo pra dormir a noite, sossegado" (Mulher, 45 anos).

\section{Quando eu casei, eu fui pra Blumenau porque meu marido tava trabalhando. Meu marido dizia que lá a gente não vivia, a gente vegetava. Dizia que aqui a gente vive. Pra criá os filho é melhor, não tem as- sim, tanta violência. Eles tão na rua. O dia que cho- ve é uma tristeza, porque aí eles não podem brincá, não pode corre. (Mulher, 38 anos)}

\section{Urbanização}

Nesse momento do processo de urbanização do município, diferentes valores entram em choque e provocam mudanças nos modos de ser, pensar e viver dos sujeitos. Antigas concepções culturais, mais tradicionais, existentes em sociedades campesinas, são confrontadas com novos valores, das sociedades urbanas e individualistas (Dumont, 1985). Os meios de comunicação exercem grande influência em transmitir esses novos ideais. No depoimento seguinte é possível entrever como as novas gerações aderem mais aos valores individualistas, urbanos, e principalmente, de classe média: "Meu quarto, ela escreveu aqui: 'Pare'. A televisão ela ganhou na primeira comunhão no lugar da festa. E, os quinze anos ela preferiu ganhar $\mathrm{R} \$ 500$ pra comprar roupa" (Mulher, 38 anos).

As próprias entrevistas mostram como vem se dando esse processo, nos relatos em que os sujeitos falam sobre tais transformações e como estão trazendo benefícios para suas vidas. A cidade está se expandindo, os meios de comunicação, a mídia e a tecnologia estão "entrando" no município com rapidez cada vez maior, e a locomoção está ficando mais fácil, devido ao asfalto estar chegando a todos os bairros: "Antônio Carlos a gente tem tudo. Não tinha banco, supermercado, padaria, hoje quantos. Tem dois bancos, acho que umas cinco padaria, farmácia, posto de saúde... é muito bom aqui” (Mulher, 69 anos).

Contudo, o avanço urbano não é recebido apenas com olhares receosos, pelo contrário, suas benesses são prontamente reconhecidas.

Hoje em dia existe a facilidade, porque, o pessoal anda bem vestido, tem muita roupa de lã, bem agasalhado, muita roupa de cama, não é mais aquela pobreza que existia há 60, 70 anos atrás. Morria tanta criança aqui o povo assim era muito trabalhador. Aquelas pessoas antigas que andavam duas horas a pé pra vim pra Igreja. (Mulher, 63 anos)

\section{Sobre o trabalho}

Ao falarem de suas vidas, mulheres e homens entrevistados enfatizaram a importância do seu trabalho, narrando não apenas aquilo que faziam, mas ressaltando também seu gosto e dedicação na realização de suas atividades. Sua identidade é marcada como "trabalhador" ou "trabalhadeira", característica atribuída pela população circundante e pelas pessoas de origem alemã a si próprias, em contraposição aos brasileiros, apontados pelos colonos como "pessoas mais alegres", que não têm tanto gosto pelo trabalho (Paquette, 1994). Os sujeitos que narraram sobre seu trabalho, destacaram o capricho com que fazem seu serviço, o gosto em fazer as coisas dessa forma: "Trabalhá, todo mundo sabe, mas o que vale mais é o capricho da pessoa" (Homem, 32 anos).

Destacaram também a diversidade de tarefas com as quais se envolvem, trabalhando "dentro" e "fora" de casa.

Eu gosto (de trabalhar fora). Por isso até que eu ajudava o meu irmão na lavoura, antes de arrumar o meu emprego. Já pensava em trabalhar em supermercado. Só que ali eu não sou só controladora de caixa, eu faço tudo. Varro a casa toda, reponho mercadoria, eu cuido do caixa, faço pagamento... já sou, como se diz, o braço direito do meu chefe. (Mulher, 31 anos)

Muitas delas se engajam em mais de um trabalho, como uma entrevistada, que além de ser responsável pelo trabalho da casa, faz bolachas para vender em cooperativa, cuida de seus jardins, e, quando necessário, trabalha como diarista, para complementar a renda familiar.

A maioria das mulheres falou da importância do trabalho doméstico, caracterizando-o como "feito com carinho e com o cuidado de quem dá muito valor". Uma entrevistada relatou o prazer em se desdobrar fazendo diferentes coisas no seu cotidiano, incluindo o cuidado da casa. No entanto, uma delas constata a invisibilidade desse trabalho, que precisa ser constantemente refeito, diariamente realizado da mesma forma.

\section{O serviço da mulher ela faz todo dia, mas não apa- rece. Lava louça agora, daqui há pouco tem que lavar de novo. Sempre é a mesma rotina e sempre tem que tá fazendo. E, às vezes, tem gente que não dá valor. Porque faz várias coisinhas, faz, faz e não aparece. (Mulher, 31 anos)}

Ao falar sobre a relação entre o trabalho doméstico e o trabalho fora de casa, vemos que ela reproduz a concepção de que o primeiro tem menor valor: é não trabalho, invisível. Mas podemos ver também que toda a família costuma participar do cuidado com a casa, e os homens têm tido maior participação, mesmo que esse trabalho seja considerado apenas uma "ajuda". Um dos entrevistados conta que faz tudo em casa, e não vê problema nisso, ao contrário de outros homens que desvalorizam o trabalho doméstico, e não têm iniciativa para fazê-lo: "Mas almoço, essas coisas eu faço. Tem muitos homens que não dão valor pras mulheres. Tem que mandar eles fazerem o serviço" (Homem, 32 anos); "Me ajuda. Quando eu não tô ele serve, faz tudo. Se eu tô ele 
também ajuda. Arruma a mesa e faz a comida. Porque ele já fazia de solteiro. Sempre ajudou" (Mulher, 45 anos).

As filhas mais jovens, por sua vez, quando já podem realizar as atividades domésticas, também o fazem na forma de ajuda, como a jovem de 15 anos, que fica em casa com a irmã, e faz o serviço em virtude da mãe trabalhar fora, como diarista: "De manhã ela fica com a pequena, faz o almoço, estuda, Eu deixo assim encaminhado. Ela lava roupa para mim, torce. Dá uma ajeitadinha na casa, arruma a cama. O que tem ela deixa tudo pronto" (Mulher, 38 anos).

O trabalho das mulheres na lavoura é referido como ajuda, da mesma forma que o trabalho doméstico feito pelos homens. Seyferth (1974) relatou algumas características do trabalho dos colonos alemães no campo, falando sobre a divisão das tarefas relativas a essas atividades. Segundo ela, geralmente as crianças ou os idosos não participavam desse trabalho, mas assim que possível, os pequenos começavam a trabalhar em tarefas secundárias à lavoura, como o cuidado de animais e a manutenção das roças. As mulheres tinham a plantação, a colheita, o cuidado da roça, dentre outras atividades, em comum com o trabalho dos homens, sendo apenas o trabalho na casa, cuidados com os filhos e a preparação dos alimentos, exclusivos a elas. Aos homens cabiam principalmente as tarefas referentes à produção, sendo exclusivo a eles a derrubada das árvores para possibilitar a plantação. Foi possível identificar que essa divisão do trabalho persiste ainda, como falou uma das entrevistadas: "Ajudo um pouco. Faço o quintal, plantá os repolho" (Mulher, 45 anos).

Esse trabalho ligado à lavoura, além do doméstico, foi tradicionalmente realizado pelas mulheres, que depois foram diversificando suas atividades, indo para o comércio, para o trabalho como diaristas, entre outros. Mas, mesmo mudando de "ramo", a maioria delas mantém um certo contato com a terra, cuidando de jardins em suas casas como é o relato da senhora que prefere ficar na roça a cozinhar: "Às vezes eu ia capiná cana, ou ia roçá pasto. Mas depois, trabalhar fora, foi uma maneira de ganhar dinheiro assim, mais fácil, porque pelo menos o trabalho, todo dia tu tá recebendo. A roça é uma coisa que não tem um retorno rápido" (Mulher, 38 anos); "Eu fui pra faculdade, mas eu não deixei de gostar de mexer na terra, isso aí é a melhor coisa que tem, é uma terapia, isso te faz um bem, te relaxa, te deixa renovada" (Mulher, 63 anos).

A população de Antônio Carlos, dedicada às atividades agrícolas, pode ser beneficiada pela aposentadoria, de um salário mínimo, através do Fundo Nacional de Assistência ao Trabalhador Rural (FUNRURAL). Para os entrevistados, a aposentadoria não significa um tempo de inatividade dedicado ao lazer, mas um reforço seguro que lhes possibilita uma continuidade mais tranquila da atividade remunerada. Assim, continuam trabalhando na produção da subsistência: "É, ele sempre dizia quando a gente ia se aposentar a gente ia de volta pro sítio. E daí deu certo. Meu marido planta um pouco, para não ficar parado. É, pro gasto, por enquanto" (Mulher, 45 anos).

\section{A configuração das casas}

As casas em Antônio Carlos podem ser categorizadas em dois modelos principais, conforme verificamos nas falas dos entrevistados. Há a "casa antiga", baseada em modelos europeus, as primeiras construídas no município. Sua planta, apesar de variações e alterações mais recentes, segue um modelo específico: uma sala de estar ampla, na frente da casa, com a qual está conectado um pequeno número de quartos, e na parte posterior, uma cozinha, que muitas vezes acaba se subdividindo em duas: uma mais "moderna", e outra onde a comida geralmente é preparada. Trata-se de uma casa de teto alto, se comparada aos modelos contemporâneos. O sótão é muitas vezes usado como quarto. A casa costumava ser um misto de alvenaria e madeira, utilizando-se de tijolos e reboco na parte externa, e de paredes de madeira para delimitar os cômodos internamente. Falando sobre as diferenças entre as casas antigas e as modernas, um dos entrevistados, que trabalha na construção civil, aponta para a qualidade das construções mais velhas:

São totalmente diferentes! A média (da altura) hoje é 2,50 metros, antigamente era 3,50 metros, 3 metros, 3,30 metros. E o reboco hoje é de cimento, antes eles... cal, barro, e óleo de baleia. Mas aguentava mais praticamente que o cimento. Antes durava 60, 70 anos, hoje eu acho que não dá. Tem assim a qualidade do material que é usada, a areia. (Homem, 32 anos)

O outro modelo é a casa de estilo "moderno", trazido da cidade, e que tem proliferado no município. A casa costuma ter telhado em quatro águas, e apenas um piso, normalmente com garagem. A distribuição dos cômodos é diferenciada da casa antiga: a sala de estar continua na parte anterior da casa, mas é afastada dos quartos e da cozinha, a qual permanece na parte posterior. O número de quartos e banheiros é maior, tendo o quarto do casal e, normalmente, um quarto para cada filho. Em algumas casas aparece a divisão da cozinha como no modelo anterior. A casa moderna é toda de alvenaria, e tem o teto mais baixo. Atualmente já podemos perceber também construções novas, em dois pisos, algumas delas com arquitetura bem moderna, fugindo aos padrões mais lineares de paredes externas e telhados.

\section{A restauração das casas antigas}

Pudemos acompanhar uma recente revaloração das casas antigas, através da restauração das mesmas. Tal movimento aconteceu após um momento de grande interesse pelo modelo moderno, e a consequente proliferação deste; e após o retorno de vários habitantes de Antônio Carlos para o município que trabalharam algum tempo em outras cidades de colonização germânica, como Blumenau-SC e Joinville-SC. Os sujeitos puderam verificar o interesse, nessas cidades, em recuperar aspectos tradicionais da cultura alemã, incluindo-se aí a restauração de antigas construções, com ajuda do governo municipal. 
Movidos por esse interesse, muitos moradores restauraram suas casas antigas, ao invés de construírem novas moradias, mesmo que esse processo tivesse tanto dispêndio monetário quanto uma construção nova, e não tivesse o apoio financeiro do município.

Isso logo foi uma idéia que eu já trouxe de lá, que se fosse pra mim cuidar dela aqui eu já ia restaurar ela. Só que aí não teve nenhum, apoio de ninguém. Isso que é ruim aqui. Em Blumenau a prefeitura faz a restauração das casa antiga, agora aqui não. $A$ gente fez tudo sozinho. (Homem, 52 anos)

A restauração das casas antigas não se refere apenas à comodidade ou à melhoria do ambiente doméstico, mas serve também para manutenção do patrimônio histórico e preservação da cultura: "É muito bom, acho bastante produtivo, é, a conservação do patrimônio histórico e arquitetônico, é sempre importante. É questão quase basilar da preservação da cultura como um todo" (Homem, 47 anos).

$\mathrm{O}$ processo de restauração não se limita à melhoria da fachada da casa, tornando-a mais bela, ou à substituição do material utilizado na construção para melhorias estruturais, mas também por reformas do interior, alterando a disposição dos cômodos e mudando a planta original.

A gente pensou, a casa tá aqui tantos anos então a gente reformando ela vai durar mais anos, então a gente pegou e reformou. É, bonita, é, hoje em dia não se faz mais... o forro, botâmo de plástico. Esse aqui também era tudo de madeira. Mas tava tudo assim muito estragado, já. (Mulher, 45 anos)

\section{As peças da casa e suas funções}

A cozinha ocupou lugar de importante entre as peças que se destacaram nas falas dos sujeitos. As referências a esta refletem a preocupação com esse ambiente da casa, que costuma iniciar logo no projeto para a construção, como atesta a fala seguinte:

Primeira coisa, quando a gente tá desenhando a casa é "faz uma cozinha grande!" Não é só as mulheres, os homens também. "A cozinha tu sabe que tem que ser grande, não pode ser pequena". Depois não cabe nem o fogão, a geladeira e a mesa. Tem televisão aqui na cozinha, dai já vai pro quarto. E muitos usavam a copa também, a sala de janta, a maioria não tá mais fazendo. Faz uma cozinha maior e já elimina aquilo ali, uma peça a menos. (Homem, 32 anos)

Essa preocupação refere-se especialmente ao tamanho do cômodo, pois é justamente nele que a família se reúne para fazer suas refeições, além de ser o local de preparo dos alimentos. É interessante notar que a mesa da cozinha costuma ser grande, com vários lugares, de modo que não se limita ao uso exclusivo da família, mas serve também para receber as visitas: "Isso já vem dos tempos antigos, né. Se vem visita a gente pára mais é na cozinha, né? (Mulher, 31 anos).

A cozinha é muitas vezes dividida em duas peças, semelhante ao que Rial (1992) encontrou nas casas de moradores da Lagoa da Conceição, em Florianópolis. Uma parte da cozinha, pouco usada, costuma ter eletrodomésticos e fogão a gás, além dos armários e outros móveis mais elaborados, com muitos enfeites e toalhas rendadas. A outra, referida em algumas falas como "área de serviço", com pouca ornamentação, é onde o trabalho de preparo de alimentos e limpeza das louças é feito, normalmente tendo também um fogão à lenha. Foi caracterizado como um local de "bagunça", em contraposição à limpeza e arrumação da outra peça.

Essa é a cozinha que eu não uso, eu faço tudo na área de serviço. É mais prático porque tem a água correndo, lavo a louça, lá, faz tudo lá. A bagunça é mais aqui fora. Porque antes eu tinha essa prá limpar e aquela, assim eu só tenho aquela. Tem que ser mais prática, né? (Mulher, 38 anos)

Outro cômodo muito utilizado por todos os familiares é a sala de televisão, apesar de esse espaço comunal estar em relação de oposição ao quarto individual, pois este, quando tem televisão, permite que cada um escolha o programa a que quer assistir: "A sala que a gente usa direto. A TV é aqui, a bagunça da pequena é aqui. Não tenho aquela sala reservada pra bonito, né. Meu marido diz 'A minha casa toda é usada" (Mulher, 38 anos).

O número pequeno de quartos, no qual costumavam dormir vários filhos, é um dos alvos de alterações nas restaurações e reformas. Procurou-se criar novas divisões entre os aposentos existentes, para que cada membro da família pudesse ter seu próprio quarto. Essa compartimentalização da casa, de forma a criar espaços individuais, deve ser apreendida a partir do horizonte da urbanização, e a consequente adoção da ideologia do individualismo (Dumont, 1985). Entretanto, atualmente, o quarto individual acaba sendo uma reivindicação, especialmente dos adolescentes, mas é também objeto de preocupação do casal, inclusive para alocação confortável dos avôs: “Ali já era tudo aberto, agora eles fizeram quarto aqueles, quarto era muito pequeno para botá junto quatro" (Mulher, 80 anos, sobre os quartos dos netos); "Mas já era grande, mas não era grande que chega. Era dois quartos. Fizeram repartição no meio, fizeram a suíte e aí ficou melhor" (Mulher, 84 anos, acerca de seus aposentos).

Ah, ficou melhor pra mim, agora eu levanto quietinha, nem precisa acendê a luz, se quisé pode que tem abajur, aí eu vô no banheiro, tomo água e volto pra cama né. Agora quando a gente qué ir numa festa, num lugar, ai tem bastante lugar, uma quer tomar banho, vai num; outro qué se arrumar, vai no outro banheiro, e dai num instantinho nós tamo pronto. (Mulher, 84 anos) 


\section{Tecnologia e meios de comunicação}

Todas as casas visitadas tinham fogão a gás, geladeira, freezer, forno elétrico e microondas, telefone, rádio, televisão, muitas vezes computador. Ao lado das casas, antenas parabólicas. Em muitas residências, carros nas garagens e "tobatas", pequenos tratores para o trabalho agrícola.

As diferentes gerações se relacionam de maeira diversa com a tecnologia. A fala da senhora a seguir é ilustrativa da forma como lida com os meios tecnológicos, em contraste com a geração de seus netos. Ela relata sua temeridade em manusear os objetos com os quais não tem familiaridade, e ressalta as facilidades que a utilização destes traz para seus netos. Isso remete ao fato da entrada de muitos desses objetos tecnológicos estar relacionada ao recente processo de urbanização que o município vivencia, processo que evidencia ainda mais as diferenças entre as gerações no lidar com as novas tecnologias.

Eu fico com medo de mexê nessas coisas, televisão, computador eu não mexo, celular a mesma coisa, pra que eu quero isso! Eu deixo pros novo, mas é bom, às vezes eles tão fora, aí eles telefonam "pai, vem me buscá”. (Mulher, 84 anos)

Em concordância com a fala desta senhora, observamos que a maioria das pessoas que portavam aparelhos celulares eram adolescentes. Porém, um casal jovem queixou-se do fato do telefone celular não ter cobertura em todo o município, limitando sua utilidade. Esse casal também nos falou sobre as vantagens que a instalação da telefonia fixa no município trouxe para o cotidiano da família: "É muito bom (o telefone). O que acontece lá, ali, a gente já sabe na hora" (Homem, 32 anos); "Melhorou bastante pra gente o telefone. Por exemplo, pra mim que estou no serviço, às vezes precisa alguma coisa pra ele, daí é bem melhor" (Mulher, 31 anos).

Outro sujeito nos relatou sobre os usos que faz da tobata. Em sua fala podemos perceber que essa cumpre diferentes funções no cotidiano da família (desde auxiliar no trabalho na roça até ser utilizada como meio de transporte para reuniões religiosas típicas da região): "Se não tivesse isso aí (tobata) não tinha nem como eu ir buscar trabalhá. Ontem à noite nós fomo na novena, é longe, lá no morro. Acho que foi vinte pessoa ali em cima. Aí botei uns banco em cima, e fomo embora" (Homem, 52 anos).

Em nossa pesquisa os meios tecnológicos que remetem a outro tempo também são valorizados e utilizados pelos informantes, como o fogão à lenha. Na seguinte fala, uma participante compara esse ao fogão a gás, dizendo que o primeiro é mais econômico. Além disso, outros sujeitos nos relataram que a comida feita em fogão à lenha é muito mais saborosa.

Durante a semana eu cozinho tudo no fogão à lenha. Lenha sempre tem. As vezes tem gente que constrói, a gente arruma uns restinho de madeira.
Porque esse fogão é econômico, qualquer sarrafinho dá,pouquinha coisinha dá prá fazer comida. (Mulher, 45 anos)

Quando interpelados sobre o que assistiam na televisão, os sujeitos revelaram uma diferença geracional quanto ao tipo de programas assistidos. Enquanto as gerações mais antigas relataram a preferência por programas de cunho religioso, as mais jovens, além de preferirem os telejornais e novelas, relataram o fato de assistirem por mais tempo à televisão: "E daí agora o que eu mais gosto de assistir é a missa, é o terço, programas religiosos" (Mulher, 69 anos); "De dia não assiste, mas à noite a televisão tá ligada direto. Primeiro é o jornal, é a minha preferência. Uma novelinha das oito e meia também gosto. Ah, eu adoro (futebol), parabólica, 90 por cento aqui tem. Pra assistir notícia local não dá, então deixa essa antena, pra assistir o local também" (Homem, 32 anos).

Outro meio de comunicação bastante usado na região é o rádio. Uma informante contou sobre a relação de pessoas que trabalham na agricultura com esta tecnologia, falando do quanto esse meio de comunicação está presente nesse espaço.

Isso aí é, se a gente se acostuma tem que ter ali ligado. Eu sei porque antes o pai plantava fumo né, e quando chegava no verão a gente ficava escolhendo no rancho, e ficava sempre com o rádio ligado. Tinha que ter porque se desligava. (Mulher, 31 anos)

\section{Considerações finais}

Em Antônio Carlos ocorre um evidente processo de urbanização, que acompanha sua incorporação à Região Metropolitana de Florianópolis, dinâmica que diz respeito às modificações no uso do solo, nas relações de trabalho, familiares, de sociabilidade, e às formas singulares como os sujeitos passam a conviver com valores urbanos.

Ao lado das antigas residências de estilo germânico e das casas mais modernas, que se confundem com as residências de alvenaria das cidades ao redor, percebemos um início de verticalização, com a construção de pequenos prédios nas áreas mais centrais do município.

A população de Antônio Carlos tem alto índice de longevidade, se distinguindo de outros municípios por ter boa qualidade de vida. As famílias se estruturam ainda em modelos mais tradicionais, hierárquicos, em que a autoridade dos pais e avós é respeitada, encontrando, os últimos, acolhida nas casas dos descendentes. O ideário individualista, com forte apelo à realização pessoal, no entanto, já se faz presente nas falas dos sujeitos mais jovens.

O movimento de restauração das casas antigas, e a construção de novas residências em estilo urbano, são expressões do franco processo de urbanização em que se encontra o município. Por outro lado, Antônio Carlos ainda é procurada por sujeitos que buscam a melhoria de qualidade de vida, seja para residir ou passar os finais de semana. Mas esse choque 
com o ideário individualista, típico da população urbana, tem acirrado o sentimento de pertencimento a uma comunidade, e consequentemente, gerando preconceito em relação aos que vêm de fora.

Pela facilitação do acesso às cidades vizinhas, verificamos a diversificação das atividades laborais, e um grande investimento na educação das novas gerações, com a tendência ao abandono da atividade agrícola como principal fonte de renda. Verificamos aumento no número de quartos, como espaço de uso individual, o que expressa a superposição dos valores do individualismo moderno urbano aos valores tradicionais da localidade. Essa sobreposição se evidencia na presença de aparatos tecnológicos mais modernos, como o forno microondas, o computador, o celular, e outros mais antigos, como o fogão à lenha, utilizados todos em uma mesma residência.

O espaço doméstico ainda marca as divisões de gênero, sendo que muitas entrevistadas falam que seus esposos e filhos às vezes fazem o almoço, arrumam a casa, mas atribuem a isso o sentido de ajuda e não de trabalho, assim como o trabalho da mulher na lavoura também é compreendido muitas vezes como ajuda. Os casais de Antônio Carlos vêm de uma longa tradição de trabalho conjunto e costumam compartilhar as atividades que desempenham no plantio e colheita e na comercialização dos produtos, nas feiras e sacolões das cidades ao redor. Este trabalho compartilhado também é percebido nas pequenas empresas de jardinagem, e nas casas comerciais de habitantes do município, na localidade e arredores.

A identificação das mulheres como trabalhadeiras aponta para a valorização do trabalho doméstico, pelo qual são as principais responsáveis, mas há também um forte movimento relacionado à busca de empregos assalariados e ênfase na capacitação de homens e mulheres, para novas formas e relações de trabalho.

\section{Referências}

Bauman, Z. (2003). Comunidade: A busca por segurança no mundo atual. Rio de Janeiro: Jorge Zahar.

Da Matta, R. (1981). Relativizando: Uma introdução à antropologia social. Petrópolis: Vozes.

Dumont, L. (1985). O individualismo: Uma perspectiva antropológica da ideologia moderna. Rio de Janeiro: Rocco.

Firestone, S. (1976) A dialética do sexo: Um manifesto da revolução feminista. Rio de Janeiro: Labor.

Fonseca, C. (1999). Quando cada caso não é um caso: Pesquisa etnográfica e educação. Revista Brasileira de Educação, 10, 58-78.

Freud, S. (1990). O mal-estar na civilização. In Freud, S., Edição Standard brasileira das obras psicológicas completas de Sigmund Freud (J. Salomão, Trad., pp. 75-171). Rio de Janeiro: Imago. (Original publicado em 1930)
Geertz, C. (1996). A interpretação das culturas. Rio de Janeiro: LTC Editora.

Geertz, C. (2005). Obras e vidas: O antropólogo como autor. Rio de Janeiro: Ed. UFRJ.

Gilligan, C. (1982). Uma voz diferente: Psicologia da diferença entre homens e mulheres da infância à idade adulta (N. C. Caixeiro, Trad.) Rio de Janeiro: Rosa dos Ventos.

Greer, G. (1974). A mulher eunuco. São Paulo: Círculo do Livro.

Lacan, J. (2002). Os complexos familiares (M. A. C. Jorge \& P. M. Da Silveira, Trads.). Rio de Janeiro: Jorge Zahar (Original publicado em 1938)

Lacan, J. (1998). Subversão do sujeito e dialética do desejo no inconsciente freudiano. In J. Lacan, Escritos (V. Ribeiro, Trad.). Rio de Janeiro: Jorge Zahar (Original publicado em 1966)

Lago, M. C. S. (1992). Memórias de uma comunidade que se transforma: Um estudo de caso do processo de urbanização de uma comunidade de origem açoriana no litoral da Ilha de Santa Catarina. Revista do Instituto Histórico e Geográfico de Santa Catarina, 11, 138-151.

Lago, M. C. S. (1996). Modos de vida e identidade: Sujeitos no processo de urbanização da Ilha de Santa Catarina. Florianópolis, SC: Ed. UFSC.

Lago, M. C. S., Serafim, C. N., \& Figueiredo, M. G. (2000). Gênero, gerações e subjetividades na Grande Florianópolis. Paidéia (Ribeirão Preto), 14, 197-209.

Laqueur, T. (2001). Inventando o sexo: Corpo e gênero dos gregos a Freud. Rio de Janeiro: Relume Dumará.

Mannheim, K. (1982). O problema sociológico das gerações. In M. M. Foracchi (Ed.), Karl Mannheim (pp. 67-95). São Paulo: Ática.

Motta, A. B. (2004). Subjetividades possíveis: Idosas e tempo geracional. In C. E. Peixoto (Org.), Família e envelhecimento. Rio de Janeiro: Ed. FGV.

Nogueira, C. (2001). Feminismo e discurso do gênero na psicologia social. Psicologia \& Sociedade, 13(1), 107128.

Oliveira, R. C. de. (2000). O trabalho do antropólogo. Brasília: Paralelo 15.

Paquette, D. (1994). Identidade, linguagem e relações interétnicas: $O$ caso dos brasileiros de origem alemã (Relatório Final de Pesquisa PIBIC/CNPQ). Florianópolis: UFSC.

Pedro, J. M. (2005). Traduzindo o debate: O uso da categoria gênero na pesquisa histórica. História, 24, 77-98.

Perrot, M. (1998). Mulheres públicas. São Paulo: Ed. UNESP.

Pomian, K. (1984). L'ordre du temps. Paris: Gallimard.

Rial, C. S. M. (1992). Da casa de antigamente à casa decorada. Ciência Hoje, 14(82), 19-24.

Scott, J. (1995). Gênero: Uma categoria útil de análise histórica. Educação \& Realidade, 20, 71-99. 
Sirinelli, J-F. (2002). A geração. In J. Amado \& M. M. Ferreira (Orgs.), Usos \& abusos da história oral (pp. 131-137). Rio de Janeiro: Ed. FGV.

Seyferth, G. (1974). A colonização alemã no Vale do ItajaíMirim. Porto Alegre: Movimento.

Stoller, R. J. (1968). Sex and gender. New York: Science House.

Mara Coelho de Souza Lago é Professora Titular do Departamento de Psicologia, docente do Programa de Pós-graduação em Psicologia e do Programa de Doutorado Interdisciplinar em Ciências Humanas da Universidade Federal de Santa Catarina.

Carolina Duarte de Souza é graduada em Psicologia pela Universidade Federal de Santa Catarina.

Erikson Kaszubowski é mestrando pelo Programa de Pósgraduação em Psicologia da Universidade Federal de Santa Catarina.

Marina Silveira Soares é graduada em Psicologia pela Universidade Federal de Santa Catarina.

Recebido: 18/05/2008

$1^{a}$ revisão: 20/03/2009

Aceite final: 12/05/2009 